\title{
Oxidative Stress and Autophagy
}

\author{
Adem Kara, Semin Gedikli, Emin Sengul, \\ Volkan Gelen and Seckin Ozkanlar
}

Additional information is available at the end of the chapter

http://dx.doi.org/10.5772/64569

\begin{abstract}
Free radical production related with many stress factors including radiation, drugs, ageing and trauma plays a key role in cell death. Notwithstanding, free radicals can cause pathology in a variety of diseases through oxidative stress: Under oxidative stress, excessive production of free radicals can trigger cell death by primarily DNA and all cellular macromolecule damages. Also, excessive free radicals have a role in early inducers of autophagy cell death upon nutrient deprivation. Autophagy is physiologic process of eukaryotic systems, which have significant role in adaptation to oxidative stress by degradation of metalloproteins and oxidatively damaged macromolecules. By oxidizing, membrane injuries allow the leakage of enzymes and contribute to cell damage. However, recent publications demonstrate the protecting role of lysosome system during excessive reactive oxygen species (ROS) production by the elimination of damaged proteins or organelles. Activation of autophagic or lysosomal system can eliminate the oxidizing components of cell in oxidative stress response. This chapter aims to provide the novel insight data for oxidative damage-mediated autophagy as well as their metabolic networks.
\end{abstract}

Keywords: oxidative stress, free radicals, autophagy, cell death

\section{Introduction}

The number of studies on oxidative stress has been increasing for the last 30 years and its effects on many illnesses' pathogenesis have been investigated. In this chapter, we focused the cellular injuries that are caused by the oxidant agents in the cell and potential relationships between oxidative stress and autophagy, that is, both cells' method of saving itself from death 
and its death mechanism at the same. We also aimed to enable the new therapeutic intervention to break oxidative stress-mediated cell injuries and promote cell surviving.

Free radicals are a molecule or atom species and they have free electron charges [1]. These free electrons show a high reactivity towards unstable agents. Free radicals are produced both in physiological conditions and in pathological conditions. Overproduced free radicals can cause injuries by reacting to the organelles such as cell membrane and DNA which are the components of cells $[1,2]$. The production of the oxidant agents, which are produced in the cell and which carry free electron pairs that are able to damage cell, is balanced by the antioxidant system $[2,3]$. The imbalance between antioxidant and oxidant system is called 'oxidative

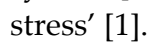

The reactive oxygen species (ROS) in biological systems including superoxide anion $\left({ }^{2} \mathrm{O}_{2}\right)$, hydroxyl radical $(\mathrm{HO})$, nitric oxide (NO), peroxyl radical (ROO) and non-radical hydrogen peroxide $\left(\mathrm{H}_{2} \mathrm{O}_{2}\right)$ compose the most important components of oxidative stress [4]. The primary source of ROS is the mitochondrial-carrying system in the cell [5]. Electrons, which weaken in the mitochondrion, turn into oxygen $\left(\mathrm{O}^{-2}\right)$ atoms and then turn into $\mathrm{H}_{2} \mathrm{O}_{2}$ by spontaneous or superoxide dismutase (SOD) catalysis. In this stage, the mitochondrial ROS amount is at the rate of $1-2 \%$ of the total oxygen consumption. Although this amount seems to be low, it is equal to one billion molecules when the intracellular ROS amount that every single cell of the body produces is calculated [6]. When it is thought that there are about 100 trillion cells in the human body, the physiological ROS amount being produced increases more. In some cases, with the effect of factors such as exceeding of energy need, decreasing of mitochondrial activity (ageing), exogenous (UV, radiation) and endogenous (oxidase and oxygenase), ROS is produced in the body in an excess quantity [7]. In addition to mitochondria, sarcolemma, sarcoplasmic reticulum and transverse tubules are of the strongest sources of ROS due to the existence of NADH/NADPH oxidase (Nox) [8]. Moreover, endoplasmic reticulum (ER), peroxisomes, plasma membrane, polymorph nuclear cells and macrophages are known as the places in which ROS is produced [9]. In the cell, the ROS produced must be kept in balance with the antioxidant system [10].

\section{Oxidative stress}

Oxidative stress plays an important role in the pathophysiology of many diseases. For this reason, the medical importance of the oxidative stress is being understood even better day by day. Especially, along with the inseparable process between oxidative stress and inflammation with molecular interactions makes this subject be more and more attractive researched area $[10,11]$. Today, for the development of new treatment options, antioxidant treatment strategies are being increasingly researched. The aim of this review is to enlighten the relation between oxidative stress and inflammation, which has a role in the physiopathogenesis of many diseases.

The production of ROS may increase in the beginning phase of the defence response of the cells during inflammation [12]. The Nox system, which settled in the plasma membranes of 
cells, contributes to ROS production by being activated during phagocytosis. Moreover, it is stated that the Nox is the primary factor contributing to the oxidative stress in the mitochondrial redox system $[13,14]$. In addition to Nox, arachidoriic acid (AA) mechanism, nitric oxide and xanthine oxidase $(\mathrm{XO})$ cause ROS production, as well [15]. AA is produced by the activation of phospholipase A2 and this may cause increase in ROS production [16]. At the same time, AA cyclooxygenase increases ROS production by activating various enzymes such as cytochrome P-450-dependent monooxygenase $\mathrm{XO}$ [17]. Xanthine oxidase is an ROS indicator, which causes more oxygen to be free as a result of hypoxanthine's degradation [18].

\section{Redox biology}

Eukaryotic cells make gene expression through multiple metabolic pathways with environmental stimulations. In the cell, ROS-sensitive transcription factors and oxidative response give the cellular warning according to the redox condition [19]. These signal proteins are two signal pathways belonging to two different families. The first of these pathways is mitogenactivated protein (MAP) kinase family and in this pathway phosphorescence occurs starting from cytoplasm and continuing to nucleus by the activities of extracellular signal regulator kinases, which are c-jun $\mathrm{N}$ terminal kinase and p38 MAP kinase. The second family is redoxsensitive signal pathway and cytoplasmic signal factor includes thioredoxin reductase, thioredoxin, nuclear factor Ref-1 and a few transcription factors (AP-1, nuclear factor kappa B (NF-kB), Nfr-1 and Egr-1). When these redox-sensitive 'sulphydryl switches' are stimulated, by passing from cytoplasm to nucleus, they trigger the transcription factors and enable the expression of specific genes [20,21].

Oxidative stress has a role in many illnesses' pathogenesis such as ischaemia/reperfusion injury, Alzheimer, Parkinson and diabetes mellitus [22]. For example, the ROS amounts effecting to the cell in cancer may result in the expression of some genes via the redox-sensitive signal pathway by causing DNA damage. These redox-sensitive signal factors play roles in many processes such as cell division, cell cycle and the survival of the cell. On the other side, it is the potential molecular target of anticancer agents. This redox-sensitive sulphydryl switches signal pathways have important characteristics for potential cancer treatment. Their characteristics are firstly being overexpressed in tumours, secondly the depression of prosurvival signal pathways when they are inhibited, thirdly the entrance of cell cycle to the arrest when this signal pathway is depressed and lastly the increase of anticancer agents' activities parallel to their inhibition [21].

\section{The importance of oxidative stress in cell biology}

It is known that ROS have both beneficial and harmful effects on the cell. Its very low concentrations can perform as the second runner in some signal transmission ways [23]. However, they can cause many oxidative injuries in many vital structures when they are 
extremely produced. In the cell, there is a dynamic relation between ROS production and antioxidant capacity. Some oxidation processes such as cysteine oxidation play roles in the dynamic regulator system inside the cell [24]. It is shown that transcriptional factors such as NF-kB, p53 and AP-1 are regulated by oxygen types [25]. For this reason, sublethal ROS production can be blocked by signal transmission ways. Especially $\mathrm{H}_{2} \mathrm{O}_{2}$ is actually the second runner for various physiological stimulations such as angiotensin inflammatory cytokines and growth factors or transforming factors [26]. There is a contradiction between the reactive oxygen types such as superoxide radicals and their physiological/pathophysiological roles. It is considered that the production of superoxide radicals can be activated by neutrophils and other phagocytes [27]. When the redox homeostasis changes, the cell is exposed to oxidative stress. As a result of the mitochondrial function disorder in case of oxidative stress, a significant decrease in the cellular energy occurs, and due to this decrease apoptosis is activated. The damages in cells occur only when ROS overcomes the biochemical defence system of the cell. ROS, especially hydroxyl radicals, can react with all biological macromolecules such as lipids, proteins, nucleic acids and carbohydrates [28]. Multiple unsaturated fatty acids continuously threaten the cellular integrity and functions for oxidative injury [28, 29]. It is known that iron, which is a transition metal, has a vital role in the beginning of new lipid radical chain reactions [30]. Lipid peroxidation is a significant biological result of ageing and oxidative damages [29]. Chemotherapy agents, radiation and numerous neurodegenerative illnesses are some sources of ROS [31]. In brief, whereas oxidative stress is a positive status in processes such as cellular proliferation and activation, it is a negative status in terms of lipid peroxidation, DNA injury and the inhibition of cell growth or in terms of its causing cell deaths.

\section{Antioxidant system}

The antioxidant enzyme system in the cell is responsible for the scavengers of $\mathrm{ROS}\left(\mathrm{O}_{2}^{-}\right.$, $\mathrm{H}_{2} \mathrm{O}^{2}$ and peroxides), which consists of superoxide dismutase, catalase (CAT) and glutathione (GSH-Px or GPx) enzymes [10, 32]. Also, antioxidant defence system is responsible for the scavengers of reactive nitrogen species (RNS). Peroxynitrite $\left(\mathrm{ONOO}^{-}\right)$is a really dangerous molecule [33] and nitrite oxide is a high reactive gas radical and it is water soluble and it can pass the cell membrane by diffusion [33, 34]. As in ROS, excessive production of oxidant types originating from NO in the cell leads to imbalance between oxidants and antioxidants, which causes irreversible damage in the cells' biomolecules and causes cell death [10].

When thioredoxin, which is an intracellular enzyme, is overexpressed, it blocks oxidative stress in the cell. It is stated that there is a dynamic relation between thioredoxin enzyme and antioxidant components, and various oxygen types [35]. It has been determined in different studies that the difference in cysteine modification can affect thioredoxin function [36]. 


\section{Oxidative stress and DNA damage}

Lipids in DNA, which is a stable molecule, can have oxidative injuries just like carbohydrates and proteins $[37,38]$. All changes in the structural integrity of genetic material occurring as a result of the endogenous or exogenous factors are described as DNA damage. The integrity of the genomic DNA is constantly under threat with the effect of environmental factors. Changes in the structure of DNA may occur endogenously during cellular events such as DNA replication and DNA recombination $[39,40]$.

It is believed that the DNA damages can be caused by oxidative stress result in mutation in the cell DNA and that it is a major reason for cancer [41,42]. As a result of oxidative DNA damage, a decrease in the cascade signal occurs, which is effective in cancer development, and gene expression, a discontinuation in transcription, genomic instability and replication failure. Oxidative DNA damage plays important roles in the development of tumourigenesis, which is related to inflammation as well as increasing the risk of cancer development [43]. Moreover, it has been reported as a result of various studies conducted that the genomic damage has important roles in cases such as chronic illnesses, cardiovascular illnesses, neurodegenerative illnesses, inflammation/infection and ageing [44]. Oxidative DNA damage is rather dangerous for cell in terms of its causing mutation in cell, affecting the cell cycle and causing cancer [45].

It is stated that oxidative damage occurs in mitochondrial DNA (mtDNA) along with the nucleus DNA. It has been determined that the oxidative damage is greater in mitochondrial DNA compared to the nucleus DNA. Among the reasons for this situation, we can count that the mitochondrial DNA is quite close to the areas that produce free radicals in mitochondria and that it is not protected by histones. What is more, factors such as that the DNA damage repair system is insufficient compared to nucleus DNA and that there is an increase in mutations according to the age cause mitochondrial DNA to get more damage [46]. The damage occurred in the DNA is seen in low levels thanks to the DNA's ability to be repaired. There is an increase in oxidative DNA damage as a result of the increase in the reactive oxygen types, decrease in the antioxidant enzyme levels and the insufficiency of DNA repair mechanisms. Depending upon the oxidative damage, single- and double-chain fractures, abasic areas and base modifications can originate or cross-linking between the DNA molecule and proteins can occur [47].

Oxide DNA base damages are generally removed in two ways. These are base excision repair and damaged oligonucleotide excision repair [48]. Nearly more than 20 major damage products, which originate as a result of oxidative DNA damage, have been determined [49]. DNA product radicals give more reaction via different mechanisms to form the last product. The type of the originating DNA modification product depends on reaction conditions such as the redox potential of the substance to react, the radical production system and the existence of oxygen. Radicals can be oxidation and reduction depending on their redox potentials and the reacting substances. Although 8-hydroxypurines and formapyrimidines can originate in both presence and absence of oxygen, they better prefer to originate in an environment with oxygen. These compounds are hemiorthoamids and they can turn into each other easily [50]. 
The most commonly used for the last products of ROS-mediated DNA damage biomarker is 8-hydroxy-2'-deoxyguanosine (8-OHdG) [51]. 8-OHdG is a mutagen that reacts with DNA

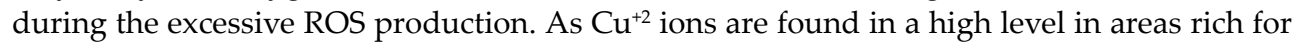
guanine-cytosine, the base which is most exposed to the oxidative damage is guanine. $\mathrm{OH}$ radical composes DNA product radicals as a result of the reaction with the atoms of guanine in positions numbered 4, 5 and 8 . $\mathrm{OH}$ product radicals of the fourth and fifth carbon atoms are dehydrated and the imidazole ring of the eighth carbon $\mathrm{OH}$ product radicals is exposed to the opening. Other DNA base damage products have less mutagenic effects. For this reason, the most commonly measured $8-\mathrm{OHdG}$ base damage product is a parameter that is widely used to determine the DNA damage $[52,53]$.

For the first time, it was determined that $8-\mathrm{OHdG}$ is an indicator of the DNA damage in 1984 by Kasai and Nishimura. Analysis of $8-\mathrm{OHdG}$, which is the major oxidation product of DNA, was reported in 1989 for the first time. There are two approaches for the analysis method of 8OHdG. The first of these, direct approach, is isolation of the DNA lesion by using physical and chemical methods and making DNA extraction and hydrolysation. The second method, indirect approach, includes the saving of DNA structure and seeing the formation of lesion in site. In this approach, measurement is made by using antibodies that have low specific features or via the activity of specific DNA repair enzymes [54, 55].

\section{Autophagy: apoptosis interaction}

In addition to the studies of Swhweichel and Merker, who researched cell death mechanism morphologically for the first time, Clarke mentioned three basic cell morphology in cell death and described apoptosis as type I, autophagy as type II and cell death, which is not lysosomal, as type III programmed cell death $[56,57]$. Apoptosis is an event characterized by cell shrinkage and chromatin condensation and cell divides into pieces called 'apoptotic bodies' in the end of the process. It has been determined that, in this type of cell death, the morphological changes occurring in the cell take place as a result of cutting DNA and proteins by proteases called caspase. The apoptotic bodies arising as a result of these fractures are resolved by lysosomes [57].

In autophagy, which is a mechanism in which intracellular macromolecules and organelles are directed to lysosomes in sachets and broken up in this mechanism, the short-lived proteins are broken up inside ubiquitin-proteasome system, intracellular organelles and long-lived proteins are benefited from as they are destroyed in autophagy system and decomposed into the building stones similar to amino acids to be used again inside the cell $[58,59]$. In the autophagic cell death, there are organelles such as cytoplasm parts, which are inside two or more layered (lipid bilayer) membrane-covered sachets, and/or mitochondria, endoplasmic reticulum. In the end, autophagy sachets form a compound with lysosome and make it possible for the material inside them to be broken up by the lysosomal enzymes [60].

Either apoptosis or autophagy, no matter what the death type is, it is known that these processes are regulated by molecular mechanisms. In the same cell, as different death cell mechanisms 
can take action even simultaneously, these mechanisms can involve each other and they cannot be distinguished easily all the time. It is difficult to describe whether the morphological changes, which come into light with the cell death mechanisms, are due to apoptosis or autophagy [61]. The reason for this can be that different cell death mechanisms have different main goals. The main goal of autophagic cell death is mainly cytoplasm, while the main goal of apoptosis is cell nucleus. Apoptosis can be sufficient for the disposal of cells with small cytoplasm. However, in cells with large cytoplasm, more than one mechanism may have to take action together. In other words, while mechanisms dispose the nucleus, cytoplasm and organelles are cleaned by the autophagy event and the cell death can be accelerated. In literature, there are studies supporting this view $[62,63]$.

\subsection{Apoptotic signals}

Caspases playing a role in apoptosis are classified in two ways:

1. Caspases starting the apoptotic signals (caspases $2,8,9,10$ ).

2. Lethal caspases that have a role in the breaking up of g-proteins (caspases 3, 6 and 7).

Along with the caspase-dependent mechanisms that control the cell death, some cell deaths are reported to be caspase-free [64]. Caspase-dependent pathway triggers cell death by activating in two ways: extrinsic and intrinsic factors. In the extrinsic pathway, tumour necrosis factor- $\alpha$ (TNF- $\alpha$ ), which is on the surface of cell membrane, connects to TNF-like ligands such as FasL or TRAIL, and causes procaspase- 8 or procaspase- 10 to be triggered and finally the apoptotic process starts [65].

In the intrinsic pathway, the failure of mitochondria results in cytochrome-C expression and then begins activations of caspases 9, 7 and 3. Another protein family having a role in the mitochondrial pathway is Bcl-2 family. It is decided whether the cell will enter apoptotic phase as a result of the interaction between Bcl-2 family members and pro-apoptotic signal molecules. The members of the Bcl-2 family are divided into three groups:

1. Anti-apoptotic group including Bcl-2, Bcl-xL and Mcl-1.

2. Group triggering apoptosis that includes Bax and Bak.

3. Group that has pro-apoptotic activity including Bad, Bik, Bid, Bim, NOXA and Puma ç.

The extrinsic pathway, also called death receptor, is a mechanism which contains cell surface receptors that generate the start of apoptosis and the formation of the death-inducing signalling complex (DISC) that is a multi-protein complex [66]. With the connection of ligand, an adaptor protein called FADD, which brings caspase 8 to DISC, becomes a part of the activity [67-69]. In the activated caspase 8, either effector caspases such as caspase 3, directly activate the apoptosis pathway or intrinsic apoptosis pathway [70]. An apoptosis pathway can be activated when the endoplasmic reticulum is under stress [71]. 


\subsection{The molecular connections between apoptosis and autophagy}

As autophagy can block apoptosis and cell death occurs as a result of both of these events, it is believed that the regulation of these mechanisms is made in coordination. Previously, it was considered that the same proteins control both of these processes. However, the latest data show that it is not true. p53 is a strong apoptosis inductive and it can also induce autophagy by increasing the expression of DRAM that is the direct p53 target gene [72]. Similarly, the activation of a well-known apoptosis inhibitor, PI3 kinase/Akt pathway, inhibits autophagy at the same time [73]. In this way, it was understood that important signal pathways could increase or decrease both apoptosis and autophagy, simultaneously. In brief, central components proteins directly regulated both apoptosis and autophagy mechanisms [74].

Beclin-1/Atg-6 is a part of the type III PI3 kinase complex, which is necessary for the formation of autophagic vesicles and the interaction with Beclin-1 can block the induction of autophagy. Beclin-1 is described as a protein that can interact with Bcl-2, as well [74]. This case shows that an apoptosis regulator physically interacts with an autophagy regulator. Beclin-1 interacts with other major anti-apoptotic Bcl-2 family (Bcl-xL) proteins, either [75]. In the regulation of these mechanisms, depending on the presence of $\mathrm{Bcl}-2$ in mitochondria and endoplasmic reticulum, in other words depending on its condition in the subcellular localization, there may be differences. The inhibition of the autophagy with Bcl-2 function takes place only in the endoplasmic reticulum, and mitochondrial-directed $\mathrm{Bcl}-2$, which is a strong inhibitor of many apoptotic stimuli, cannot inhibit autophagy $[75,76]$. Another mechanism that is able to control the autophagy via Bcl-2 was located in endoplasmic reticulum [77]. In this method, Bcl-2 blocks calcium passage in endoplasmic reticulum instead of interacting with Beclin-1. Calcium activates $\mathrm{Ca}^{2+} /$ calmoduline-dependent kinase, kinase- $\beta$ and adenosine monophosphate (AMP)-activator protein kinase. This case causes mTOR inhibition to activate autophagy. By this way, permission was given to Bcl-2 for autophagy inhibition instead of apoptosis inhibition in two completely different mechanisms [78].

Extrinsic death pathway, which is one of the best-described key components of apoptosis process, can control autophagy, as well. The connection of FADD adaptor protein to the liganddependent death receptor is a necessary step for the formation of DISC. DISC accompanies death receptor signals with FADD, which acts as a platform in which caspase 8 dimerization and activation take place. FADD includes two protein areas, one death area and one death effector area, which interact with each other. The death area of the FADD can, unexpectedly, induce a new cell death mechanism, which includes really high levels of autophagy in normal epithelium cells. Actually, as FADD death area does not have catalytic activity, it is possible that it induces autophagy by interacting with other proteins. The interesting point is that autophagy response can be observed more easily when apoptosis stops and this case supports that the apoptosis and autophagy in normal epithelium cells are simultaneously induced by FADD death area [79].

These cases, mentioned above, show that the components of the apoptosis mechanism, which are regulated by intrinsic and extrinsic pathways, could control autophagy, as well. Contrary to this case, there are studies expressing that autophagy regulators control apoptosis. These experiments, which analyse autophagic cell death originating from interferon and Atg-5, show 
that FADD can interact with Atg-5 [80]. The conducted study showed that this interaction ends with cell death only in a way that requires FADD and caspases, without the formation of autophagic vesicles. From this study, the conclusion that Atg- 5 can regulate extrinsic apoptosis pathway components is drawn. Another mechanism, which is about the ability of Atg-5 for regulating apoptosis, was described. The key step in this mechanism is to provide the activation of intrinsic apoptosis pathway that can be blocked by Bcl-2 and to compose a protein form, which is translocated to mitochondria in order to start the cytochrome-C oscillation. To be able to realize this, Atg-5 must be cut by calpain. The general importance of this mechanism is supported by the information that Atg-5 knock-down protects tumour cells against a kind of apoptosis stimulation. This case can still be complex and as the cutting of Atg- 5 by calpain can cause a formation of protein, which is not able to activate autophagy, it is possible for calpain activity to increase or decrease autophagy [81]. There are some studies showing that calpain activity is necessary for autophagy, which is induced by the lack of rapamycin and amino acid [79].

\subsection{Autophagy: type II cell death}

Autophagy is a death mechanism characterized by the degradation of cellular components, and plays roles in the pathophysiology of many diseases' [82, 83]. The damaged cellular components and contents are removed by lysosomal autophagy. In case of increasing the autophagic effect with oxidative stress or physiological stimulations, protein synthesis and energy output pathways, cell organelles and proteins are disrupted in the cells. Also, under

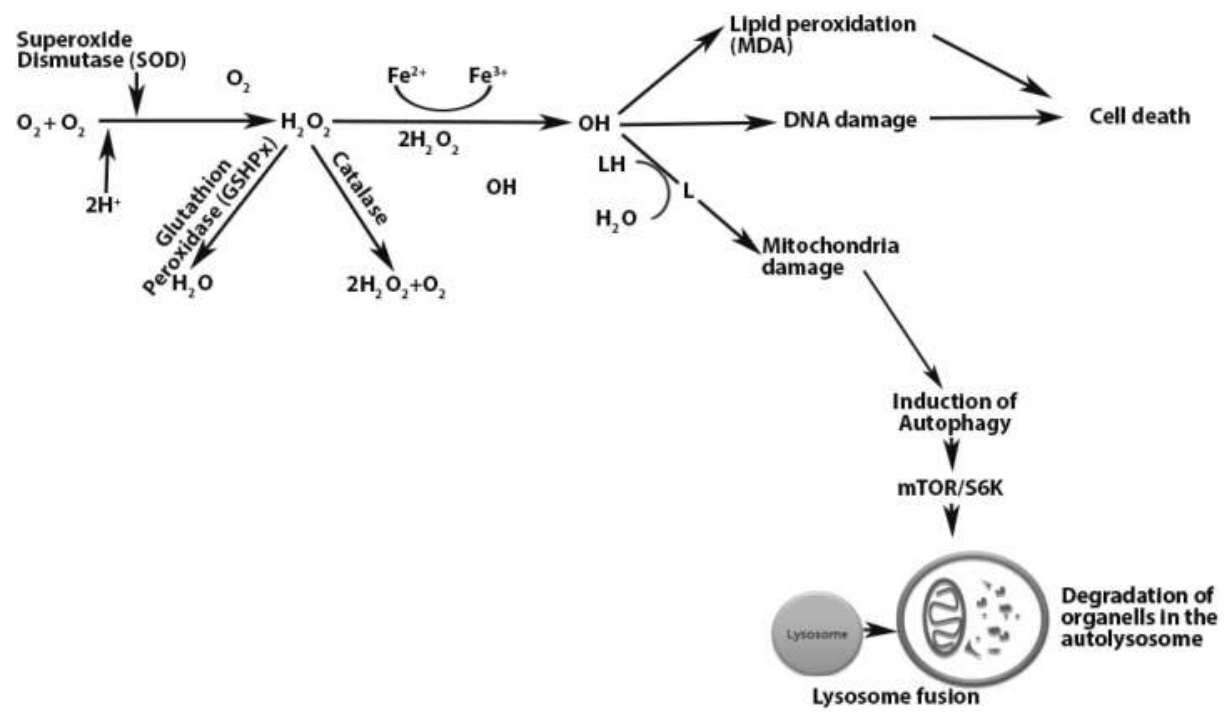

Figure 1. Oxidative stress-mediated cell damages in the cell: Excessive ROS production can lead to damages in mitochondria, which can cause cell death or oxidative-damaged cell components are degraded by autophagy and promote cell survival. 
limited food intake, autophagy provides internal energy sources [82, 83]. With this effect of lysosomal autophagy, cell can survive in case of oxidative stress. This survival system occurring in the cell is stimulated by stress factors such as hunger, hyperthermia and hypoxia [84]. mTOR (mammalian target of rapamycin), which is a factor playing important role in autophagic activation, is a kinase signal pathway. This signal pathway is classically activated in case of hunger, hypoxia or stress condition [83].

In eukaryotic cells, the first step of the oxidative damage is antioxidant defence system and the second step is lysosomal autophagy [85]. In the second step, damaged cell components such as proteins, organelles or DNA are removed with lysosomal autophagy [82]. This defence system provides degradation of these components and cell surviving. In the third defence step, there is type II cell death (autophagy). Severe damaged and not repaired cells are removed by autophagy and the organ's integrity is ensured [86] (Figure 1).

Autophagy is also activated in many cases of metabolic and therapeutic stress such as the lack of growth factor in the cell, signal inhibition of receptor tyrosine kinase/Akt/mTOR metabolic pathway, ischaemia/reperfusion, intracellular calcium accumulation and endoplasmic reticulum stress $[87,88]$. Increased production of ROS stimulates the initiation of autophagy in association with stress signal pathways. For this, cysteine protease Atg- 4 inactivation is made with ROS accumulation in the cell. This inactivation results in Atg-4 phosphoethanolamine precursor accumulation, which is also necessary for the beginning of autophagosome [89]. In this way, under stress condition, oxidative damaged cell components are degraded by autophagy and continue its life by this way. There is a complex relation between cell death and stress adaptation [90]. The molecular relationship between cell death and autophagy has not been completely understood nowadays.

While autophagic cell death is the main cell death seen during the development, it has been reported in recent studies that apoptosis-induced cell death can be connected or related to autophagy [78, 91]. The signal cross-talk between apoptosis and autophagy can be related to $\mathrm{Bcl}-2$ gene family. Moreover, it has been shown that Bcl-2 family proteins inhibit the apoptosis and autophagy [75, 92]. The association between the anti-apoptotic Bcl-2 protein and the autophagic Beclin-1 protein has an important role in the point of convergence of the apoptotic and autophagic cell death. In the autophagic process, Bcl-2 protein has an important role in autophagosome formation via Beclin-1 network [75]. Also, anti-apoptotic Bcl-2 proteins inhibit the Beclin-1-dependent autophagic cell death [93].

The antioxidant effect of anti-apoptotic Bcl-2 proteins has been reported. This anti-apoptotic protein decreases the production of reactive oxidants and inhibits the apoptotic cell death [94]. By this way, the overexpressed Bcl-2 and decreasing ROS level probably cause the repression of cytochrome-C from mitochondrion and the prevention of death cell [95]. As mentioned above, ROS creates a connection between cellular stress and the starting of autophagy, and autophagosome formation is started by stimulating Atg-8-phosphoethanolamine precursor accumulation [89]. 


\section{Summary and future perspective}

Endogenous and exogenous stress factors that cells are exposed to trigger the ROS production in the cell, which causes damages in cellular organelles. Oxidative response is a part of normal cellular physiology and halts the organelles' damages in the cells and promotes cell surviving. While autophagy is a type II cell death, it is also an alternative defence system that cell chooses to be able to survive in cells which are exposed to oxidative damage. Autophagy can provide the removal of damaged organelles with lysosomal autophagy and ensures cell to survive. Autophagy plays an important role in both detecting oxidative stress and removing oxidatively damaged proteins and organelles, as well as the cellular machineries responsible for excessive ROS/RNS production. Investigations into the specific molecular targets of ROS in the autophagy pathway and the specific signalling mechanisms will be important for our understanding of biology and diseases.

\section{Author details}

Adem Kara $^{1 *}$, Semin Gedikli ${ }^{1}$, Emin Sengul ${ }^{2}$, Volkan Gelen ${ }^{4}$ and Seckin Ozkanlar ${ }^{3}$

*Address all correspondence to: ademkara36@gmail.com

1 Faculty of Veterinary, Department of Histology and Embryology, Ataturk University, Erzurum, Turkey

2 Faculty of Veterinary, Department of Physiology, Ataturk University, Erzurum, Turkey

3 Faculty of Veterinary, Department of Physiology, Kafkas University, Erzurum, Turkey

4 Faculty of Veterinary, Department of Biochemistry, Ataturk University, Erzurum, Turkey

\section{References}

[1] Halliwell B. Free radicals and other reactive species in disease. New York, John Wiley \& Sons, Ltd, eLS. 2005.

[2] Kara A, Akman S, Ozkanlar S, et al. Immune modulatory and antioxidant effects of melatonin in experimental periodontitis in rats. Free Radical Biology and Medicine. 2013;55:21-6.

[3] Kara A, Yücel A, Yücel N, Özcan H, Selli J and Ünal D. Evaluation of the combined treatment with cisplatin and melatonin on neuroblastoma cell viability and antioxidant capacity. Journal of Experimental and Clinical Medicine. 2014;31. 
[4] Babior BM. Phagocytes and oxidative stress. The American Journal of Medicine. 2000;109:33-44.

[5] Chance B, Sies H and Boveris A. Hydroperoxide metabolism in mammalian organs. Physiological Reviews. 1979;59:527-605.

[6] Wagner BA, Venkataraman S and Buettner GR. The rate of oxygen utilization by cells. Free Radical Biology and Medicine. 2011;51:700-12.

[7] Filomeni G, Rotilio G and Ciriolo M. Disulfide relays and phosphorylative cascades: partners in redox-mediated signaling pathways. Cell Death and Differentiation. 2005;12:1555-63.

[8] Powers SK and Jackson MJ. Exercise-induced oxidative stress: cellular mechanisms and impact on muscle force production. Physiological Reviews. 2008;88:1243-76.

[9] Samoylenko A, Hossain JA, Mennerich D, Kellokumpu S, Hiltunen JK and Kietzmann T. Nutritional countermeasures targeting reactive oxygen species in cancer: From mechanisms to biomarkers and clinical evidence. Antioxidants and Redox Signaling. 2013;19:2157-96.

[10] Filomeni G, De Zio D and Cecconi F. Oxidative stress and autophagy: the clash between damage and metabolic needs. Cell Death and Differentiation. 2015;22:377-88.

[11] Hensley K, Robinson KA, Gabbita SP, Salsman S and Floyd RA. Reactive oxygen species, cell signaling, and cell injury. Free Radical Biology and Medicine. 2000;28:145662.

[12] Taverne YJ, Bogers AJ, Duncker DJ and Merkus D. Reactive oxygen species and the cardiovascular system. Oxidative Medicine and Cellular Longevity. 2013;2013.

[13] Kuroda J, Ago T, Matsushima S, Zhai P, Schneider MD and Sadoshima J. NADPH oxidase 4 (Nox4) is a major source of oxidative stress in the failing heart. Proceedings of the National Academy of Sciences. 2010;107:15565-70.

[14] Dale DC, Boxer L and Liles WC. The phagocytes: neutrophils and monocytes. Blood. 2008;112:935-45.

[15] Pou S, Keaton L, Surichamorn W and Rosen GM. Mechanism of superoxide generation by neuronal nitric-oxide synthase. The Journal of Biological Chemistry. 1999;274:957380.

[16] Davis LM, Rho JM and Sullivan PG. UCP-mediated free fatty acid uncoupling of isolated cortical mitochondria from fasted animals: correlations to dietary modulations. Epilepsia. 2008;49:117-9.

[17] Zuo L, Christofi FL, Wright VP, Bao S and Clanton TL. Lipoxygenase-dependent superoxide release in skeletal muscle. Journal of Applied Physiology. 2004;97:661-8. 
[18] Nanduri J, Vaddi DR, Khan SA, Wang N, Makerenko V and Prabhakar NR. Xanthine oxidase mediates hypoxia-inducible factor-2alpha degradation by intermittent hypoxia. PLoS One. 2013;8:e75838.

[19] Chuang Y-YE, Chen Y, Chandramouli V, et al. Gene expression after treatment with hydrogen peroxide, menadione, or t-butyl hydroperoxide in breast cancer cells. Cancer Research. 2002;62:6246-54.

[20] Hirota K, Matsui M, Murata M, et al. Nucleoredoxin, glutaredoxin, and thioredoxin differentially regulate NF-kB, AP-1, and CREB activation in HEK293 cells. Biochemical and Biophysical Research Communications. 2000;274:177-82.

[21] Cook JA, Gius D, Wink DA, Krishna MC, Russo A, Mitchell JB. Oxidative stress, redox, and the tumor microenvironment. Semin Radiat Oncol. 2004;14(3):259-66. Review.

[22] Kannan K and Jain SK. Oxidative stress and apoptosis. Pathophysiology. 2000;7:15363.

[23] Suzuki YJ, Forman HJ and Sevanian A. Oxidants as stimulators of signal transduction. Free Radical Biology and Medicine. 1997;22:269-85.

[24] Pennisi E. Superoxides relay Ras protein's oncogenic message. Science. 1997;275:15678.

[25] Morel Y and Barouki R. Repression of gene expression by oxidative stress. Biochemical Journal. 1999;342:481-96.

[26] Ushio-Fukai M, Alexander RW, Akers M and Griendling KK. p38 mitogen-activated protein kinase is a critical component of the redox-sensitive signaling pathways activated by angiotensin II role in vascular smooth muscle cell hypertrophy. Journal of Biological Chemistry. 1998;273:15022-9.

[27] Babior BM. Oxygen-dependent microbial killing by phagocytes. New England Journal of Medicine. 1978;298:659-68.

[28] Jaeschke H. Mechanisms of oxidant stress-induced acute tissue injury. Experimental Biology and Medicine. 1995;209:104-11.

[29] Reiter RJ, Guerrero JM, Garcia JJ and Acuña-Castroviejo D. Reactive oxygen intermediates, molecular damage, and aging: relation to melatonin. Annals of the New York Academy of Sciences. 1998;854:410-24.

[30] Sies H. Biochemistry of oxidative stress. Angewandte Chemie International Edition in English. 1986;25:1058-71.

[31] Kannan K, Holcombe RF, Jain SK, et al. Evidence for the induction of apoptosis by endosulfan in a human T-cell leukemic line. Molecular and Cellular Biochemistry. 2000;205:53-66. 
[32] Flohé L. Changing paradigms in thiology: from antioxidant defense toward redox regulation. Methods in Enzymology. 2010;473:1-39.

[33] Di Giacomo G, Rizza S, Montagna C and Filomeni G. Established principles and emerging concepts on the interplay between mitochondrial physiology and S-(de) nitrosylation: implications in cancer and neurodegeneration. International Journal of Cell Biology. 2012;2012.

[34] Stamler JS, Singel DJ and Loscalzo J. Biochemistry of nitric oxide and its redox-activated forms. Science-New York Then Washington. 1992;258:1898.

[35] Casagrande S, Bonetto V, Fratelli M, et al. Glutathionylation of human thioredoxin: a possible crosstalk between the glutathione and thioredoxin systems. Proceedings of the National Academy of Sciences. 2002;99:9745-9.

[36] Haendeler J, Hoffmann J, Tischler V, Berk BC, Zeiher AM and Dimmeler S. Redox regulatory and anti-apoptotic functions of thioredoxin depend on S-nitrosylation at cysteine 69. Nature Cell Biology. 2002;4:743-9.

[37] Wang C, Li Z, Zhang Q, Zhao M and Liu W. Enantioselective induction of cytotoxicity by $\mathrm{o}, \mathrm{p}^{\prime}$-DDD in PC12 cells: implications of chirality in risk assessment of POPs metabolites. Environmental Science and Technology. 2013;47:3909-17.

[38] Doganlar O and Doganlar ZB. Effects of a mixture of volatile organic compounds on total DNA and gene expression of heat shock proteins in Drosophila melanogaster. Archives of Environmental Contamination and Toxicology. 2015;68:395-404.

[39] Kulaksız G and Sancar A. Nükleotid eksizyon onarımı ve kanser (Nucleotide excision repair and cancer). Türk Biyokimya Dergisi (Turkish Journal of Biochemistry). 2007;32:104-11.

[40] Yan S, Sorrell M and Berman Z. Functional interplay between ATM/ATR-mediated DNA damage response and DNA repair pathways in oxidative stress. Cellular and Molecular Life Sciences. 2014;71:3951-67.

[41] Hussain SP, Hofseth LJ and Harris CC. Radical causes of cancer. Nature Reviews Cancer. 2003;3:276-85.

[42] Hosoya N and Miyagawa K. Targeting DNA damage response in cancer therapy. Cancer Science. 2014;105:370-88.

[43] Bartsch H and Nair J. Chronic inflammation and oxidative stress in the genesis and perpetuation of cancer: role of lipid peroxidation, DNA damage, and repair. Langenbeck's Archives of Surgery. 2006;391:499-510.

[44] Kawanishi S and Inoue S. (Damage to DNA by reactive oxygen and nitrogen species). Seikagaku The Journal of Japanese Biochemical Society. 1997;69:1014-7.

[45] Dryden Jr GW, Deaciuc I, Arteel G and McClain CJ. Clinical implications of oxidative stress and antioxidant therapy. Current Gastroenterology Reports. 2005;7:308-16. 
[46] Lim KS, Jeyaseelan K, Whiteman M, Jenner A and Halliwell B. Oxidative damage in mitochondrial DNA is not extensive. Annals of the New York Academy of Sciences. 2005;1042:210-20.

[47] Ercan N and Fidanci UR. Oxidative DNA damage products and diseases (Oksidatif DNA Hasar Ürünleri ve Hastalıklar). Dicle Univ Vet Fak Derg. 2012;2:40-57.

[48] Evans MD, Dizdaroglu M and Cooke MS. Oxidative DNA damage and disease: induction, repair and significance. Mutation Research/Reviews in Mutation Research. 2004;567:1-61.

[49] de Souza Machado AA, Hoff MLM, Klein RD, et al. Oxidative stress and DNA damage responses to phenanthrene exposure in the estuarine guppy Poecilia vivipara. Marine Environmental Research. 2014;98:96-105.

[50] Dizdaroglu M, Jaruga P and Rodriguez H. Measurement of 8-hydroxy-2'-deoxyguanosine in DNA by high-performance liquid chromatography-mass spectrometry: comparison with measurement by gas chromatography-mass spectrometry. Nucleic Acids Research. 2001;29:e12.

[51] Lu X and Yu C. Enantiomer-specific profenofos-induced cytotoxicity and DNA damage mediated by oxidative stress in rat adrenal pheochromocytoma (PC12) cells. Journal of Applied Toxicology. 2014;34:166-75.

[52] Barroso MF, De-Los-Santos-Alvarez N, Delerue-Matos C and Oliveira MBPP. Towards a reliable technology for antioxidant capacity and oxidative damage evaluation: electrochemical (bio) sensors. Biosensors and Bioelectronics. 2011;30:1-12.

[53] Wang C, Yang J, Lu D, Fan Y, Zhao M and Li Z. Oxidative stress-related DNA damage and homologous recombination repairing induced by $\mathrm{N}, \mathrm{N}$-dimethylformamide. Journal of Applied Toxicology. 2015; 936-945.

[54] Valavanidis A, Vlachogianni T and Fiotakis C. 8-hydroxy-2'-deoxyguanosine (8OHdG): a critical biomarker of oxidative stress and carcinogenesis. Journal of Environmental Science and Health Part C. 2009;27:120-39.

[55] Collins AR, Rašlová K, Somorovská M, et al. DNA damage in diabetes: correlation with a clinical marker. Free Radical Biology and Medicine. 1998;25:373-7.

[56] Schweichel JU and Merker HJ. The morphology of various types of cell death in prenatal tissues. Teratology. 1973;7:253-66.

[57] Clarke PG. Developmental cell death: morphological diversity and multiple mechanisms. Anatomy and Embryology (Berlin). 1990;181:195-213.

[58] Ohsumi Y. Molecular dissection of autophagy: two ubiquitin-like systems. Nature Reviews Molecular Cell Biology. 2001;2:211-6.

[59] Shintani T and Klionsky DJ. Autophagy in health and disease: a double-edged sword. Science. 2004;306:990-5. 
[60] Levine B and Yuan J. Autophagy in cell death: an innocent convict? Journal of Clinical Investigation. 2005;115:2679-88.

[61] Betin VM and Lane JD. Caspase cleavage of Atg4D stimulates GABARAP-L1 processing and triggers mitochondrial targeting and apoptosis. Journal of Cell Science. 2009;122:2554-66.

[62] Kroemer G, Marino G and Levine B. Autophagy and the integrated stress response. Molecular Cell. 2010;40:280-93.

[63] Mehrpour M, Esclatine A, Beau I and Codogno P. Overview of macroautophagy regulation in mammalian cells. Cell Research. 2010;20:748-62.

[64] Pradelli LA, Beneteau M and Ricci JE. Mitochondrial control of caspase-dependent and -independent cell death. Cell Molecular Life Science. 2010;67:1589-97.

[65] Schrader K, Huai J, Jockel L, Oberle C and Borner C. Non-caspase proteases: triggers or amplifiers of apoptosis? Cell Molecular Life Science. 2010;67:1607-18.

[66] Thorburn A. Death receptor-induced cell killing. Cellular Signalling. 2004;16:139-44.

[67] Thomas LR, Johnson RL, Reed JC and Thorburn A. The C-terminal tails of tumor necrosis factor-related apoptosis-inducing ligand (TRAIL) and Fas receptors have opposing functions in Fas-associated death domain (FADD) recruitment and can regulate agonist-specific mechanisms of receptor activation. Journal of Biological Chemistry. 2004;279:52479-86.

[68] Chinnaiyan AM, O'Rourke K, Tewari M and Dixit VM. FADD, a novel death domaincontaining protein, interacts with the death domain of Fas and initiates apoptosis. Cell. 1995;81:505-12.

[69] Boatright KM, Renatus M, Scott FL, et al. A unified model for apical caspase activation. Molecular Cell. 2003;11:529-41.

[70] Luo X, Budihardjo I, Zou H, Slaughter C and Wang X. Bid, a Bcl2 interacting protein, mediates cytochrome $C$ release from mitochondria in response to activation of cell surface death receptors. Cell. 1998;94:481-90.

[71] Boyce $M$ and Yuan J. Cellular response to endoplasmic reticulum stress: a matter of life or death. Cell Death Differentiation. 2006;13:363-73.

[72] Crighton D, Wilkinson S, O'Prey J, et al. DRAM, a p53-induced modulator of autophagy, is critical for apoptosis. Cell. 2006;126:121-34.

[73] Arico S, Petiot A, Bauvy C, et al. The tumor suppressor PTEN positively regulates macroautophagy by inhibiting the phosphatidylinositol 3-kinase/protein kinase B pathway. The Journal of Biological Chemistry. 2001;276:35243-6.

[74] Liang $\mathrm{XH}$, Jackson S, Seaman $\mathrm{M}$, et al. Induction of autophagy and inhibition of tumorigenesis by Beclin 1. Nature. 1999;402:672-6. 
[75] Pattingre S, Tassa A, Qu X, et al. Bcl-2 antiapoptotic proteins inhibit Beclin 1-dependent autophagy. Cell. 2005;122:927-39.

[76] Zhu W, Cowie A, Wasfy GW, Penn LZ, Leber B and Andrews DW. Bcl-2 mutants with restricted subcellular location reveal spatially distinct pathways for apoptosis in different cell types. The EMBO Journal. 1996;15:4130-41.

[77] Høyer-Hansen M, Bastholm L, Szyniarowski P, et al. Control of macroautophagy by calcium, calmodulin-dependent kinase kinase-beta, and Bcl-2. Molecular Cell. 2007;25:193-205.

[78] Shimizu S, Kanaseki T, Mizushima N, et al. Role of Bcl-2 family proteins in a nonapoptotic programmed cell death dependent on autophagy genes. Nature Cell Biology. 2004;6:1221-8.

[79] Thorburn A. Apoptosis and autophagy: regulatory connections between two supposedly different processes. Apoptosis. 2008;13:1-9.

[80] Pyo JO, Jang MH, Kwon YK, et al. Essential roles of Atg5 and FADD in autophagic cell death: dissection of autophagic cell death into vacuole formation and cell death. The Journal of Biological Chemistry. 2005;280:20722-9.

[81] Yousefi S, Perozzo R, Schmid I, et al. Calpain-mediated cleavage of Atg5 switches autophagy to apoptosis. Nature Cell Biology. 2006;8:1124-32.

[82] Cuervo AM. Autophagy: in sickness and in health. Trends in Cell Biology. 2004;14:707.

[83] Levine B. Eating oneself and uninvited guests: autophagy-related pathways in cellular defense. Cell. 2005;120:159-62.

[84] Moore MN, Allen JI and McVeigh A. Environmental prognostics: an integrated model supporting lysosomal stress responses as predictive biomarkers of animal health status. Marine Environmental Research. 2006;61:278-304.

[85] Moore MN. Diet restriction induced autophagy: a lysosomal protective system against oxidative-and pollutant-stress and cell injury. Marine Environmental Research. 2004;58:603-7.

[86] Lockshin RA and Zakeri Z. Apoptosis, autophagy, and more. The International Journal of Biochemistry and Cell Biology. 2004;36:2405-19.

[87] Lum JJ, Bauer DE, Kong M, et al. Growth factor regulation of autophagy and cell survival in the absence of apoptosis. Cell. 2005;120:237-48.

[88] Ogata M, Hino S, Saito A, et al. Autophagy is activated for cell survival after endoplasmic reticulum stress. Molecular and Cellular Biology. 2006;26:922031. 
[89] Scherz-Shouval R, Shvets E, Fass E, Shorer H, Gil L and Elazar Z. Reactive oxygen species are essential for autophagy and specifically regulate the activity of Atg4. The EMBO Journal. 2007;26:1749-60.

[90] Fulda S, Gorman AM, Hori O and Samali A. Cellular stress responses: cell survival and cell death. International Journal of Cell Biology. 2010;2010.

[91] Yu L, Alva A, Su H, et al. Regulation of an ATG7-beclin 1 program of autophagic cell death by caspase-8. Science. 2004;304:1500-2.

[92] Akar U, Chaves-Reyez A, Barria M, et al. Silencing of Bcl-2 expression by small interfering RNA induces autophagic cell death in MCF-7 breast cancer cells. Autophagy. 2008;4:669-79.

[93] Pattingre S and Levine B. Bcl-2 inhibition of autophagy: a new route to cancer? Cancer Research. 2006;66:2885-8.

[94] Chen ZX and Pervaiz S. BCL-2: pro-or anti-oxidant? Front Bioscience (Elite Ed). 2009;1:263-8.

[95] Mirkovic N, Voehringer DW, Story MD, McConkey DJ, McDonnell TJ and Meyn RE. Resistance to radiation-induced apoptosis in Bcl-2-expressing cells is reversed by depleting cellular thiols. Oncogene. 1997;15:1461-70. 